\title{
Mast Cell Concentrations in Peripheral and Central Giant Cell Granulomas: Is there any Angiogenetic Role?
}

\author{
Sareh Farhadi ${ }^{1}$, Fatemeh Shahsavari ${ }^{1}$, Ferial Taleghani $^{2 *}$, Elaheh Komasi $^{3}$
}

\begin{abstract}
Background: In the maxillofacial region, giant cell granulomas occur in 2 clinical forms, central and peripheral. Despite histopathological similarity between these 2 forms totally different clinical behaviors have been reported. The present study was undertaken to compare mast cell and vascular concentrations in these pathologic lesions. Materials and Methods: In this cross-sectional descriptive study, 20 pathological samples of central giant cell granuloma (CGCG) and 20 samples of peripheral giant cell granuloma (PGCG) were selected and examined through toluidine blue staining for mast cell assessment and immunohistochemical staining by VEGEF antibody for comparing the number of mast cells. T-test, chi-squared test and backward multivariate linear regression were used for statistical analysis using SPSS 20. Statistical significance was set at $P<0.05$. Results: This study showed significantly greater VEGF expression and mast cell concentrations in CGCG compared to PGCG cases. Also there was a significant correlation between VEGF expression and the concentration of mast cells. No relation was found between age, sex and site of the lesion and concentration of mast cells or VEGF expression. Conclusions: It is feasible that higher concentrations of mast cells in CGCG versus PGCG samples might lead to more aggressive clinical behavior via vascular proliferation and angiogenesis. However, other biologic mechanisms should be considered in this situation.
\end{abstract}

Keywords: Central giant cell granuloma - peripheral giant cell granuloma - mast cells - angiogenesis - VEGF

Asian Pac J Cancer Prev, 17 (2), 673-676

\section{Introduction}

Giant cell granuloma is a lesion with proliferation of giant cells in a mesenchymal stroma (Kujan et al., 2015). In maxillofacial region this lesion occurs in 2 clinical forms; despite histopathological similarity between these 2 forms their clinical behaviors are totally different.

Central giant cell granuloma (CGCG) is recognized as an intraosseous tumor while peripheral giant cell granuloma (PGCG) is considered a common tumor-like lesion of the oral cavity, which also can be considered a reactionary lesion (Newiel etal., 2008; Shojaei et al., 2015). On the other hand, there is important evidence regarding the role of angiogenesis in different stages of tumor formation and according to some studies mast cells have an important role in the angiogenesis process (Jahanshahi et al., 2012; Manpreet et al., 2012).

Mast cells were introduced by Paul Ehrlich for the first time in 1877 and described as Mastzellan (Kessler et al., 1967). The role of these cells is clear in host defense mechanisms. They also play a role in allergic reactions and anaphylactic shock. These cells have characteristics that enable them to play a role in a broad range of biological activities (Varsha et al., 2014). Their wide biological characteristics, wide distribution and strategic deployment near blood vessels, nerves, inflamed tissues and neoplastic masses enable them to play an important role in many pathological, immunological and physiological processes (Church etal., 1997; Tan et al., 2004).

Chemotaxis of mast cells near tumors is independent from the presence of inflammatory mediators and results in secretion of chemical substances (chemoattractants) by tumoral cells such as IL-3, FGF-2 and SCF. So, formation of paracrine loop which results in chemotaxis of mast cells and level of these chemical substances in stroma around tumor has a relation with progression and aggressiveness of tumor (Gruber et al., 1995).

Mast cells secrete a wide range of mediators. Some of these mediators act as an irritant to tumors and promote tumor production and some have inhibitory effects on malignancies (Theoharides et al., 1982).

Therefore, since mast cell concentrations are higher in some highly aggressive tumors compared to less aggressive ones (Dabbous et al., 1991) and since some studies have shown that vascular concentration is considerably higher in aggressive giant cell granuloma of the jaws compared to less aggressive ones (Peacock et al., 2012), comparison of mast cells and vascular concentrations between these 
two clinical forms of giant cell granuloma might be useful in evaluating the differences in their clinical behaviors. To the best of our knowledge, no study to date has compared mast cell concentrations in CGCG and PGCG of the jaws. Therefore the aim of the present study was to compare mast cell and vascular concentrations in CGCG and PGCG.

\section{Materials and Methods}

In this cross-sectional descriptive study, 20 pathological samples of CGCG and 20 samples of PGCG were selected and examined from the archives of Razi Pathology Laboratory in Rasht.

The paraffin blocks were selected and two 4-micron sections were prepared from each block, one for staining with toluidine blue for mast cell assessment and one for immunohistochemical staining through vascular endothelial growth factor (VEGF) antibody.

\section{Toluidine blue staining}

After preparation of 5-micron tissue sections from the paraffin blocks and placing them on dry-heat, preparations were made for toluidine blue staining according to instructions .

Figure 1. Toluidine blue staining of central giant cell granuloma sections under $\times 400$ magnification. Mast cells are shown by arrow.

\section{Immunohistochemical staining steps}

First 4-micron sections were prepared from the paraffin blocks for immunohistochemical staining, followed by deparaffinization by placing the blocks in xylene. Then alcohol was dehydrated at different temperatures and $0.03 \%$ hydrogen peroxide and then washed in PBS (phosphate-buffered saline) for 3 minutes. Subsequently, for the process of antigen recovery they were placed in a microwave under a pressure of $2 \mathrm{~atm}$ and a temperature of $120^{\circ} \mathrm{C}$ and cooled at room temperature for 20 minutes.

After the slides were washed in PBS they were subjected to primary antibody at room temperature for 30 minutes and then subjected to secondary antibody, followed by washing in PBS, being subjected to DAB chromogen and being counter-stained by Meyer's hematoxylin. Then the slides were placed in rising concentrations of alcohol and xylene, and coated by Entellan and mounted (Seifi et al., 2012).

After preparation of slides the mast cells were counted and recapitulated by 2 observers in 10 random views under a light microscope at $\times 400$. In the next step 10 random fields were examined at $\times 400$ for assessment of expression of VEGF. The results were reported as $>50 \%$ and $\leq 50 \%$.

Figure 2. VEGF Immunohistochemical staining of central giant cell granuloma section at $\times 400$ magnification showed expression of $>50 \%$.

The first observer was an oral and maxillofacial pathologist and the second was a dental student who was trained by the pathologist for this purpose. It is necessary to point out that counting was carried out without awareness about the type of the lesion.

In the end the counts determined by the two observers for all the slides as well as all the information regarding the patients' sex and age were analyzed.

\section{Statistical analysis}

Independent t-test was used to compare the number of mast cells between central and peripheral giant cell granulomas. Chi-squared test was used to compare VEGF expression between the two groups. In addition, backward multivariate linear regression was used to assess the effect of variables such as sex, age and site of the tumor on mast cell and vascular concentrations. Furthermore, t-test was used was used to assess the relationship between the number of mast cells and expression of VEGF in central and peripheral lesions. SPSS 20 was used for all the statistical analyses at $\mathrm{P}<0.05$.

\section{Results}

\section{Mast cell concentrations}

As shown in Table 1 the minimum and maximum mast cell counts in CGCG were 28 and 86, respectively with a mean and standard deviation of 59.05 and 15.37, respectively.

In the PGCG the minimum and maximum mast cells counts were 19 and 59, respectively, with a mean and

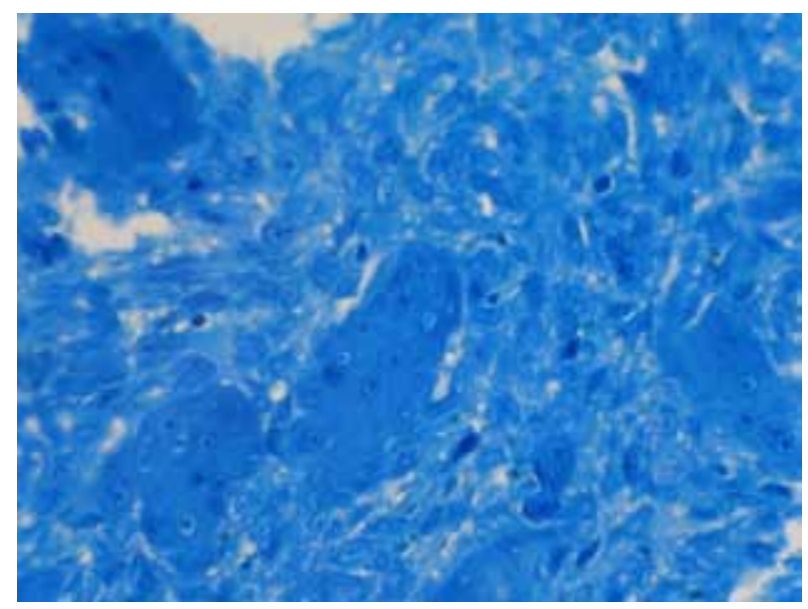

Figure 1. Toluidine Blue Staining of Central Giant Cell Granuloma Sections Under ×400 Magnification

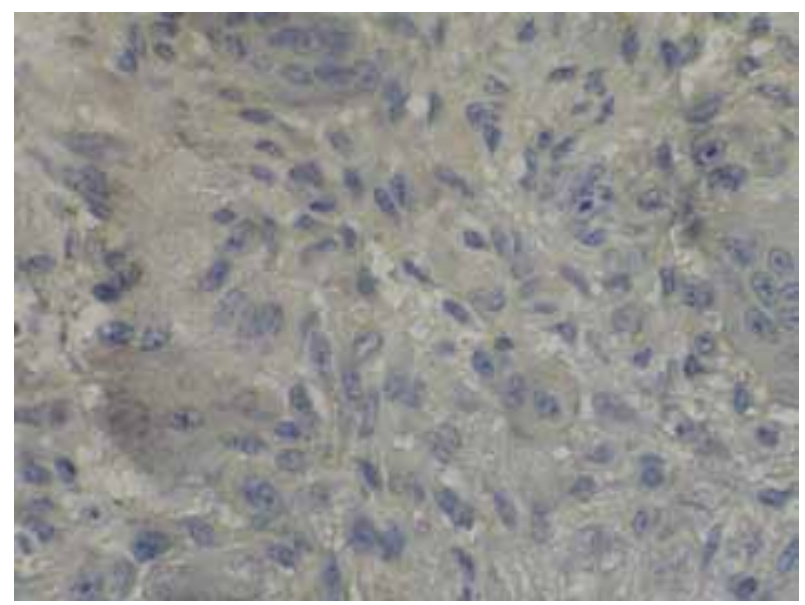

Figure 2. VEGF Immunohistochemical Staining of Central Giant Cell Granuloma Section at $\times 400$ Magnification Showed Expression of $>\mathbf{5 0 \%}$ 
Table 1. The Overall Data for Mast Cell Observations

\begin{tabular}{cccccc}
\hline Lesion & Samples & $\begin{array}{c}\text { Maximum amount } \\
\text { of mast cells }\end{array}$ & $\begin{array}{c}\text { Minimum amount } \\
\text { of mast cells }\end{array}$ & Mean & SD \\
\hline Central & 20 & 86 & 28 & 59.05 & 15.37 \\
Peripheral & 20 & 59 & 19 & 34.95 & 11.18 \\
\hline
\end{tabular}

Table 2. Comparison of Vascular Concentrations in CGCG and PGCG

\begin{tabular}{ccccc}
\hline & & VEGF $>50$ & VEGF $<50$ & Total \\
\hline \multirow{2}{*}{ Lesion } & central & 16 & 4 & 20 \\
& peripheral & 5 & 15 & 20 \\
Total & 19 & 21 & 19 & 40 \\
\hline
\end{tabular}

Table 3. Relation Ship between Vascular Concentrations and Mast Cell Concentration

\begin{tabular}{lccc}
\hline VEGF & Number & Mean & SD \\
\hline$>50 \%$ & 21 & 54.09 & 19.51 \\
$<50 \%$ & 19 & 39.15 & 12.53 \\
\hline
\end{tabular}

standard deviation 34.95 and 11.18, respectively.

Statistical analysis regarding comparison of mast cell and vascular concentrations in these two groups was as follows: Mast cell concentration exhibited a significant difference between central and peripheral giant cell granulomas, with significantly higher counts in CGCG compared to PGCG.

\section{VEGF expression}

Comparison of VEGF expression in CGCG and PGCG: Table 2 shows VEGF expression in CGCG, with $\leq 50 \%$ in 4 samples and $>50 \%$ in 16 samples. Furthermore, it was $\leq 50 \%$ in 15 cases and $>50 \%$ in 5 cases of PGCG samples.

According to chi-squared test, VEGF expression exhibited a significant difference in CGCG and PGCG $(\mathrm{P}<0.001)$.

In this study a significant correlation was found between VEGF expression and concentration of mast cells, indicating that lesions with higher VEGF expression exhibited higher concentrations of mast cells.

Correlation of age, sex and site of the lesion with mast cell counts and VEGF expression

For assessment of the effect of sex and age on mast cell counts and vascular concentration, linear regression was used and no relationship was found between age, sex and site of the lesion and concentration of mast cells and angiogenesis.

\section{Discussion}

The results of this study, showed significant differences in VEGF expression and mast cell concentration between CGCG and PGCG. This means that VEGF expression and mast cell concentrations were higher in CGCG compared to PGCG. Also there was a significant correlation between VEGF expression and concentration of mast cells. Also no relation was found between age, sex and site of the lesion and concentration of mast cells and angiogenesis.

Peacock et al demonstrated the level of vascular concentration and angiogenesis in aggressive giant cell granuloma compared to the non-aggressive one (Peacock et al., 2012). In their CGCG samples with more aggressive behavior, VEGF expression was higher and as VEGF is one of the mediators released by mast cells it can be claimed that mast cells can increase vascular concentration and result in more aggressive behavior.

Furthermore, Susarla et al demonstrated that the density of stained CD34 as one of the vascular markers was higher by $2.5 \%$ in aggressive lesions and less than $2.5 \%$ in giant cell granuloma (Susarla et al., 2009). Farahani et al demonstrated that mast cells have a role in collagen synthesis by fibroblasts and microscopic differences in soft tissue lesions, which can cause different degrees of fibrosis in these lesions; in addition, mast cell counts were significantly lower in PGCG compared to IFH and POF (Farahani et al., 2010). Some other studies demonstrated that aggressive lesions have higher BFGF compareding to non-aggressive ones (Peacock et al., 2012). PGCG is less aggressive as it has lower mast cell counts, which coincide with the results of the present study. Also similar results were achieved in a study by Reddy et al in relation to collagen synthesis by fibroblasts and the probable role of mast cells in the development and progression of the lesions evaluated, which coincide with the results of the present study (Vandana et al., 2014).

Mast cells have a broad range of function, physiological characteristics, wide distribution and strategic deployment near blood vessels, nerves, inflamed tissues and neoplastic masses, enabling them to play an important role in many pathological, immunological and physiological processes (Gomez et al., 2005; Rojas et al., 2005; Costa et al., 2009; Parizi et al., 2010; Manpreet et al., 2012). In addition, these differentiated cells selectively secrete unique granules or distinctive mediators. (Theoharides et al., 1982). Furthermore, immunohistochemical studies have shown a close relationship and close proximity of mast cells with blood vessels around tumors similar to fibroblasts; therefore, irritating effects of mast cells on angiogenesis or fibroblast or their roles within tumors are more important than inhibitory effects by heparin and fibroblasts. (Samoszuk et al., 2003; Samoszuk et al., 2005).

As a result, based on the results of the present study, mast cell counts and VEGF expression are higher in CGCG than PGCG and it seems that in these lesions the mediators secreted from mast cells selectively affect angiogenesis, resulting in an increase in vascular concentration and probably leading to more aggressive clinical behavior of CGCG compared to PGCG.

In conclusion, It seems higher concentrations of mast 


\section{Sareh Farhadi et al}

cells in CGCG samples versus PGCG might lead to aggressive clinical behavior via vascular proliferation and angiogenesis. However, any other biologic mechanisms should be considered in this situation

\section{References}

Church M, Levi-Schaffer F (1997). The human mast cell. $J$ Allergy Clin Immumol, 99, 155- 60.

Costa NL, Oton-Leite AF, Cheim-Junior AP, et al (2009). Density and migration of mast cells in lip squamous cell carcinoma and actinic cheilitis. Histol Histopathol, 24, 457-65.

Dabbous MK, Haney L, Nicolson GL (1991). Mast cell modulation of tumor cell proliferation in rat mammary adenocarcinoma 13762NF. Br J Cancer, 63, 873-8.

Farahani SS, Navabazam A, Ashkevari FS (2010). Comparison of mast cells count in oral reactive lesion. Pathol Res Practice, 15, 151-5.

Gomes AP, Johann JE, Lovato GG, et al (2008). Comparative analysis of the mast cell density in normal oral mucosa, actinic cheilitis and lip squamous cell carcinoma. Braz Dent $J, 19,186-9$.

Gruber B1, Marchese MJ, Kew R (1995). Angiogenesis factors stimulate mast cell migration. Blood, 86, 2488-93.

Jahanshahi G, Sabaghian M (2012). Comparative immunohistochemical analysis of angiogenesis and mast cell density in oral normal mucosa and squamous cell carcinoma. Dent Res J (Isfahan), 9, 8-12.

Karla M, Rao N, Nanda K, et al (2012). The role of mast cell on angiogenesis in oral squamous cell carcinoma. Med Oral Patol Oral Cir Bucal, 17, 190-6.

Kessler DA, Langer RS, Pleiss NA (1967) Mast cells and tumor angiogenesis. Int J Cancer, 18, 703-9.

Kujan O, Al-Shawaf AZ, Azzeghaiby S, et al (2015). Immunohistochemical comparison of p53, Ki-67, CD68, vimentin, $\alpha$-smooth muscle actin and alpha-1-antichymotrypsin in oral peripheral and central giant cell granuloma . $J$ Contemporary Dental Practice, 16, 20-4.

Parizi AC, Barbosa RL, Parizi JL, et al (2010). A comparision between the concentration of mast cells in squamous cell carcinoma of the skin and oral cavity. An Bras Dermatol, 85, 811-8.

Peacock ZS, Jordan RC, Schmidt BL (2012). Giant cell lesions of the jaws: does the level of vascularity and angiogenesis correlate with behavior? J Oral Maxillofac Surgeons, 70, 1860-6.

Reddy V, Bhagwath SS, and Reddy M (2014). Mast cell count in oral reactive lesion; a histochemical study. Dent Res $J$ (Isfahan), 11, 187-92.

Rojas IG, Spencer ML, Martinez A, et al (2005). Characterization of of mast cell subpopulations in lip cancer. J Oral Patho Med, 34, 268-73.

Samoszuk M, Kanakubo E, Chan JK (2005). Degranulating mast cells in fibrotic regions of human tumors and evidence that mast cell heparin interferes with the growth of tumor cells through a mechanism involving fibroblasts. BMC Cancer, 5, 121- 2 .

Samoszuk M, Corwin M, Yu H (2003). Inhibition of thrombosis in melanoma allografts in mice by endogenous mast cell heparin. Thromb Haemost, 90, 351-60.

Seifi S, Shafaee S, Bizhani A, et al (2012). Evaluation of mast cell and blood vessel density in inflammatory periapical lesion. J Mash Dent Sch, 36, 121-32.

Shojaei S, Jamshidi S, Roshanaei G, et al (2015). Immunohistochemical expression of mast cell in oral reactive lesions. J Dent Shiraz Univ Med Science, 16, 10-4.

Susarla SM, August M, Dewsnup N, et al (2009). CD34 staining density pre dicts giant cell tumor clinical behavior. J Oral Maxillofacial Surgery, 67, 951-5.

Tan ST, Wallis R, He Y ( 2004). Mast cells and hemangioma. Plast Reconst Surg, 113, 999-1011.

Theoharides T, Bondy P, Tsakalos N (1982). Differential release of serotonin and histamine from mast cell. Nature, 297, 229-31.

Varsha VK, Halliker K, Girish HC, et al (2014). Expression of CD34 and CD68 in peripheral giant cell granuloma and central giant cell granuloma. J Oral Maxillofac Pathol, 18, 341-8. 